\section{Evolution and Ethics}

Nearly half a century ago Prof. T. H. Huxley, in a brilliant lecture on "Evolution and Ethics", pointed out that the view that Darwinism signifies nothing more than striving after personal or national mastery at all costs is a crude misconception of this great principle. The evolution of man himself embodies not only his physical structure but also all other attributes which have made him what he is : it involves the progressive development of standards of personal and social ethics and makes the welfare of the human race the highest purpose of the life of the individual and of the community. Material progress is only one aspect of such development, and the world is being reminded every day that it can be used as a destroying agency as well as a civilizing influence. In spite, however, of these prostituted activities, it must be acknowledged that the advance of science has, on the whole, led to the alleviation of human suffering and an increase in the capacity and the facilities for happiness. Any action-whether in peace or war-which makes degrading uses of scientific discovery and invention should be condemned by all who believe that in the evolution of man other factors are involved than those of the race to the swift and the battle to the strong. Prof. Conklin makes a most eloquent plea for the understanding of this high mission of science in the address on "Science and Ethics" delivered before the American Association for the Advancement of Science and published in the present issue of Nature. The social aspects of scientific teaching and principles were also the subject of an address on "Science and Citizenship" delivered before the Science Masters' Association on January 5. It is only by action in the spirit of these addresses that we may hope for, or expect, any advance in the ethical evolution of man himself or of civilization, which is the expression of his activities.

\section{The Services of Engineering to Mankind}

NeARLy a century ago, Dr. Samuel Smiles realized the fundamental importance to civilization of the work of the engineer and correctly estimated the interest it must have for the public. In explaining his books he wrote, "Our engineers may be regarded in some measure as the makers of modern civilisation", and he records that in a letter to him Cobden wrote, "it cannot be doubted that each succeeding generation will hold in higher estimation those discoveries in physical science to which mankind must attribute henceforth so largely its progress and improvement". These views are brought to mind by the announcement made as to its aims by the Engineering Public Relations Committee, which has recently been formed on the initiative of the Institution of Civil Engineers acting in conjunction with the leading engineering organizations in London, with Sir Clement Hindley as its first chairman. Its function is to present to the public, in suitable form, information concerning the science and practice of engineering and its service to civilization. Through the ordinary channels of information, prominence is given to the spectacular side of such undertakings as the building of the Queen Mary, the construction of the Mersey Tunnel and that of the Sydney Harbour Bridge, to mention only three great works of the last few years, but this treatment tends to obscure from public view the knowledge of the ceaseless efforts being put forth to understand more fully the works of Nature and so to harness them to the service of mankind. It is only thus that such vast undertakings can be attempted with prospect of success.

IMPROVEMENTS in the manufacture of iron and steel and other materials and in the methods of using these products to meet the changing needs of the time, advances in the design and construction of engines and machine tools, new applications of electric, hydraulic and pneumatic energy and of the refrigerating principle are but a few of the lines on which advancement is being made. At the present time, it would appear that an era of the importance of alloy metals is beginning; by their means combinations of properties are being obtained such as open up new possibilities for the engineer. With the extension of the use of metals, more and more of the work of the world comes within his province, and it is therefore most desirable that the accomplishments, purposes and possibilities of the several branches of engineering should be more fully and more generally understood. The Committee proposes by means of lectures for schools and colleges, by exhibitions, and by co-operation with the Press, the British Broadcasting Corporation and the news film companies, to get into touch with the public. Efforts will also be made to work in conjunction with engineering societies outside London and with all bodies interested in engineering. The secretary and public relations officer is Lieut.-Colonel F. H. Budden, whose address is at 1-7 Great George Street, S.W.I.

\section{Selection for Post-Primary Education}

Dr. W. P. Alexander gave a paper at a meeting in connexion with the recent conference of the National Union of Teachers to members engaged in higher education, on "Methods of Selection for PostPrimary Education". He emphasized the need for basing any system of selection on the capacity of the pupils to profit by the type of education to be followed. As at present arranged, selection is based rather on good work done in the junior school, instead of on the grounds of the child's capacity to profit by the education offered. The first most important factor is general mental energy, expressing itself primarily in words, and this ability should be the basis of selection for the grammar school type of education, or in terms of things, showing itself as practical or technical ability. In addition, however, there is required for success in life the character quality of determination. How these requirements are to be tested is a matter for research, some at least of which has already been done. Dr. Alexander suggested that the first selection need only be very simple tests in English and arithmetic, in order to know if the child has sufficient facility to begin post- 
primary education. For the second selection we need tests to measure general mental energy in conjunction with verbal ability or with technical ability. Lastly, in the absence of reliable tests for character qualities, the considered opinions of the school staff could be utilized. Not only would this method be simpler than the one now in operation, but it would also free the primary schools from the examination fetish. Having ascertained how many pupils there are who have the capacity to profit by the grammar school or advanced technical instruction, the necessary facilities must be provided. For the others, senior modern schools with sufficient variation to allow for the varying degrees and types of capacities among the pupils are needed.

\section{Research of the Royal College of Surgeons}

THE scientific report of the Royal College of Surgeons of England for the past year reveals the extraordinary diversity of work which is being carried out in the Museum, Research Laboratories and the Buckston Browne Surgical Research Farm, in spite of the fact that work has been severely handicapped by a rebuilding programme which will give the College of Surgeons a unique research unit. There has been great activity in almost every field. In the Museum, the Pathological Curator reports consider. able progress in the renewing of the pathological series, and in the fields of physical anthropology there have been large accessions of human material from archæological excavations in Great Britain and abroad. As for the purely research activities of the College, these have been carried on, although under difficult conditions, in temporary laboratories at St. Bartholomew's Medical School and at the Buckston Browne Research Farm. To mention only a few of the outstanding investigations which have been pursued in the course of the year, great progress has been made in the development of operative technique for the treatment of certain forms of heart disease, technique which has been most successful in its clinical applications. Work on the physiology of the urinary system has done much to solve the problem of the nervous control of the pelvis and ureter. Experimental research on nerve grafting, begun the previous year, has been continued, and is producing results which are of the greatest interest. Of particular importance from a practical point of view is the work on high blood pressure, which disease has been reproduced in the experimental animal, and has been found to resemble closely in its clinical features and histology arterial hypertension in the human. A fundamental problem which has been tackled is that of the relation of the central nervous system to carbohydrate metabolism and heat regulation, and we look forward with considerable interest to the further fruits of these investigations.

\section{Publications of the Linnean Society}

THE first part of the Proceedings of the Linnean Society for the 150th session (1937-38) has appeared. It contains the acta of the Society at meetings from that of October 28 to that of December 9 ; it em- bodies in full three of the papers read at the meetings, and abstracts of the others, whether reserved for printing in the Journal of the Society or not. It is exactly a hundred years since the Society began to print the Proceedings. At first they appeared two to five times during a session, in sheets of eight or sixteen pages, by which method during the ten years 1838-1848 the average interval between the making of a communication to the Society and its record in print was six months; and during the seven years 1848-1855 it was seven months. In 1856 the Society began to issue its Proceedings of an entire year after the end of the session and continued to do so for seventy-four years, except that between 1860 and 1872 they appeared each year in two, three or four parts as ready.

In 1930 , the Society reverted to publication by sheets, issuing sixteen pages together or multiples of sixteen. There were nine parts containing the acta of the session 1930-31; but, as this entailed excessive charges for postage, the parts were enlarged in order to reduce their number so that they were in the successive years six, five, four and five. In 1935 it was determined that four should be the number of parts in each year ; and so it remains. The part, just issued is the first part for the session 1937-38. The interval between the reading of the first paper recorded in it and its appearance from the press has been only two months. Slight changes have been made in the format by the use of bold type and spacing so as to make the record fall conveniently into chapters, and to lead the reader quickly to what he wishes to find. The Society is to continue its endeavour to obtain an attractive, as well as a prompt, publication.

Safeguards Against Interruptions of the Electric Supply

THE public and industry now use electricity so largely that any interruption in the continuity of the supply is a serious matter which needs careful consideration. Two factors that accentuate this need are first the increasing growth and interconnexion of generating plant, leading to increased risk of serious damage on the occurrence of a fault, and secondly the increasing tendency to faults occasioned. by the extended use of overhead lines for long. distance interconnexion and for supplying rural areas. In a paper on this subject read to the Institution of Electrical Engineers on January 6 by H. W. Clothier, B. H. Leeson and H. Leybourn, a full statement of the problem is given, and the best way of countering the risks run are considered for the various methods of supply. Particulars are given of high-speed smalloil-volume switches capable of breaking the circuit by utilizing in improved ways well-tried principles, and of an automatic reclosing 132 kilovolt oil circuitbreaker with an arc-duration of only one cycle of the current at full rating. It is claimed that when a fault has developed in a component of a supply system provided with protective safeguards of the automatic instantaneous protection type and fastacting circuit-breakers, very little damage if any is done to the faulty component and there is practically 